\title{
Pode a genética definir quem deve se beneficiar das cotas universitárias e demais ações afirmativas?
}

\author{
SÉrgio D.J. PENA e MARIA Cátira Bortolini
}

I have a dream that my four children will one day live in a nation where they will not be judged by the color of their skin but by the content of their character.

Martin Luther King

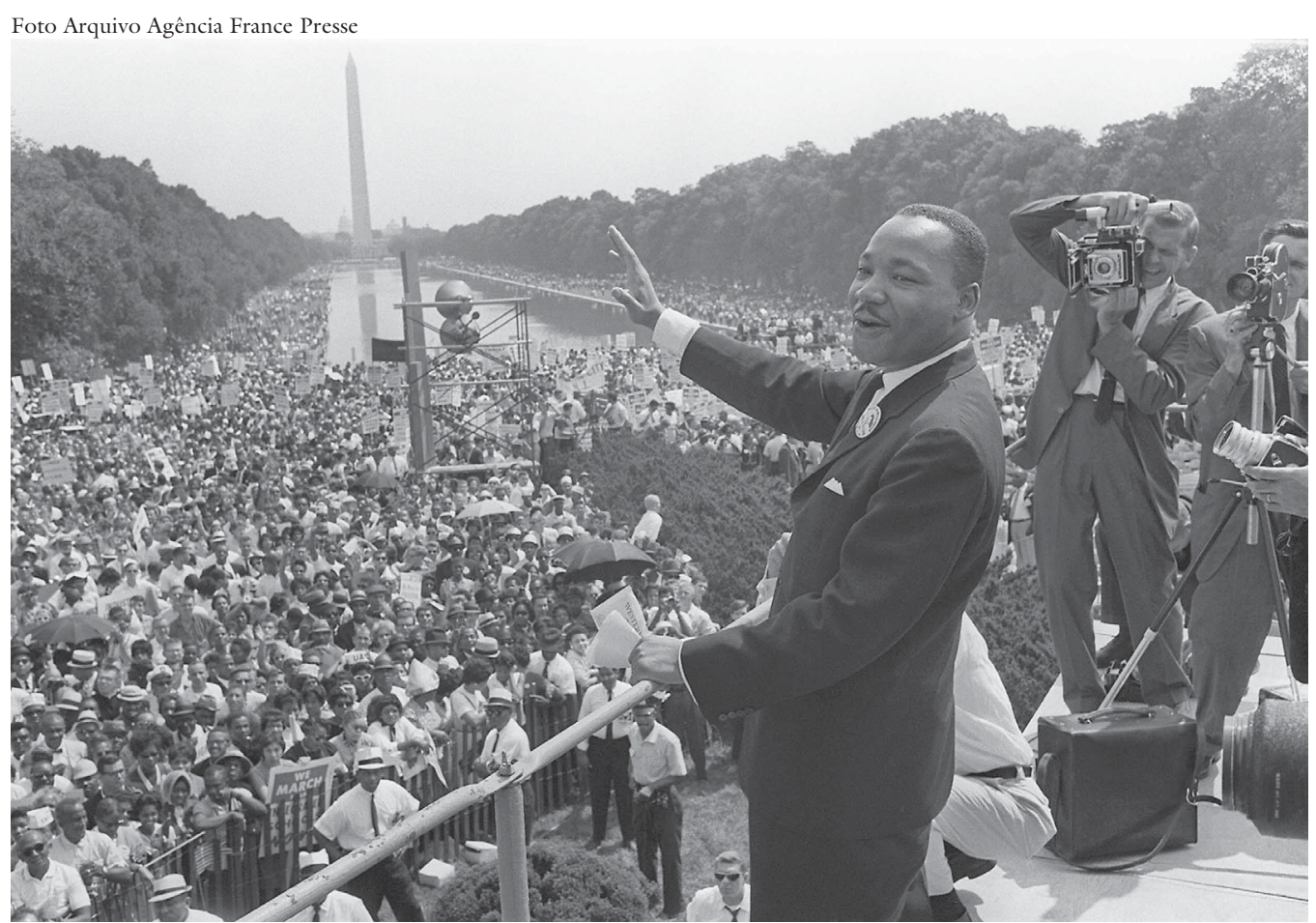

O lider Martin Luther King acena para a multidão em 28 de agosto de 1963, no espelho d'água em frente ao monumento de Washington, nos EUA, durante a "Marcha a Washington".

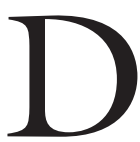
E ACORDO com o sonho de Martin Luther King, uma sociedade justa deveria tratar todos cidadãos igualmente, independente da cor da pele. Isto significaria a extinção do racismo com todas as suas perversas conseqüências: discriminação, exploração, opressão, exclusão social. A genética moderna já endossou essa postura ao mostrar que raças humanas simplesmente não existem do ponto de vista biológico. Na sua "Declaração sobre Raça” a Associação NorteAmericana de Antropologia afirma: 
Dado o nosso conhecimento a respeito da capacidade de seres humanos normais serem bem-sucedidos e funcionarem dentro de qualquer cultura, concluímos que as desigualdades atuais entre os chamados grupos raciais não são conseqüências de sua herança biológica, mas produtos de circunstâncias sociais históricas e contemporâneas e de conjunturas econômicas, educacionais e políticas (AAA, 1998).

Neste novo milênio, temos perfeitas condições de construir uma sociedade verdadeiramente igualitária, uma "democracia racial” na prática, e não apenas no papel.

Existe na sociedade brasileira uma série de desigualdades, que se manifesta especialmente por meio da exclusão socioeconômica de determinados grupos, entre eles o dos negros ${ }^{1}$ (Munanga, 2003). Deve-se deixar claro, no entanto, que se trata de uma desigualdade conjuntural, produto de um processo histórico de escravidão e racismo pois, como já se afirmou, não existe desigualdade biológica estrutural. Aristóteles já alertava em sua Ética a Nicômaco que tratar igualmente os desiguais constitui injustiça. Assim, vários segmentos da sociedade brasileira têm argumentado que já é hora de se iniciar ações corretivas para sanar esta situação de desigualdade, adotando políticas públicas compensatórias de ação afirmativa, entre as quais a reserva de vagas universitárias, agora amplamente discutida.

O Estado do Rio de Janeiro foi pioneiro em legislar nessa área, por meio da Lei no 3708, de 9 de novembro de 2001 e do Decreto nํㅜ 30.766, de 4 de março de 2002, reservando, para "negros e pardos", 40\% das vagas relativas aos cursos de graduação oferecidas pela Universidade do Estado do Rio de Janeiro (UERJ) e pela Universidade Estadual do Norte Fluminense Darcy Ribeiro. De acordo com o artigo $5^{\circ}$ daquele decreto, “a identificação dos alunos negros e pardos se fará através de declaração firmada, sob as penas da Lei, pelo próprio candidato à vaga na universidade". Segundo a Secretaria Especial de Políticas de Promoção da Igualdade Racial (Seppir), seis outras universidades públicas já implementaram cotas (vide https://www.planalto.gov.br/seppir/not/nt68.htm) e mais treze instituições estão em processo de discussão para a implantação de vagas. Entretanto, o critério de aplicabilidade das cotas varia amplamente. Como vimos, o Decreto n⿳ 30.766 do Estado do Rio de Janeiro adota a autodeclaração do indivíduo como critério de seleção. Já a Universidade Federal do Mato Grosso utilizou fotos enviadas pelos estudantes, de modo a poder selecionar os que teriam direito às vagas. Dentre os 530 candidatos que se declararam negros na seleção para ingresso em 2004, 76 foram rejeitados porque não possuíam o "fenótipo" exigido, ou seja, "lábios grossos, nariz chato e cabelos pixaim", na definição de um dos membros da comissão encarregada de analisar as fotos apresentadas pelos candidatos (Corrêa, 2003). Já o Projeto de Lei Ordinária no 340/ 2003, de Pernambuco, estabelece que o critério para ser beneficiado pelas cotas é "firmar autodeclaração de afrodescendência”. Esta heterogeneidade de critérios inevitavelmente ocasionará problemas e confusões. 
O que se pretende neste artigo, portanto, é fornecer subsídios para este tema, usando o instrumental da genética molecular e da genética de populações para discutir a contribuição africana para a formação da população brasileira. Iniciaremos com a revisão de alguns princípios da evolução humana e da diáspora africana, e, em seguida, discutiremos dois pontos relevantes: a proporção de afrodescendentes entre os brasileiros e o significado, em termos de ancestralidade genômica, dos rótulos "branco, preto e pardo" na população brasileira. Finalmente, abordaremos a pergunta-título deste trabalho: pode a genética definir quem deve se beneficiar das cotas universitárias e demais ações afirmativas?

\section{Homo sapiens sapiens: Gênese na África e Dispersão}

O homem moderno (Homo sapiens sapiens) surgiu na África, há apenas cerca de130 mil anos atrás. Recentemente, foram encontrados na Etiópia três crânios fossilizados de hominídeos que foram datados de 160-154 mil anos (White e cols. 2003; Haile-Salassie e cols. 2004). Estes hominídeos, denominados Homo sapiens idaltu, apresentavam características intermediárias entre os tipos mais arcaicos do Homo sapiens e aqueles com características modernas, constituindose assim na mais recente e poderosa evidência fóssil do surgimento do Homo sapiens sapiens na África.

A origem única e relativamente recente do homem moderno, na África, é também suportada por três linhas de evidência genética. A primeira é a observação de que os maiores níveis de diversidade genética do globo são encontrados ao Sul do Saara, na África. A interpretação deste achado é de que, quanto mais antiga a população, mais tempo teria para o acúmulo de mutações em suas estruturas genéticas. Assim, as populações com maior variabilidade devem ser as mais antigas. As análises filogenéticas fornecem uma segunda linha de evidência. A partir do trabalho pioneiro do grupo de pesquisadores liderados por Allan Wilson da Universidade da Califórnia (Cann e cols. 1987), praticamente todos os estudos baseados no DNA mitocondrial produziram árvores filogenéticas que mostravam a primeira bifurcação separando as populações africanas das demais. Da mesma maneira, árvores construídas a partir de outros conjuntos de marcadores, sejam autossômicos ou localizados nos cromossomos sexuais $\mathrm{X}$ e $\mathrm{Y}$, apresentavam tipologias muito semelhantes. Em terceiro lugar, temos as datações feitas com base no relógio molecular (isto é, mutações neutras que ocorrem de forma regular ao longo do tempo) que mostram datas de coalescência para o DNA mitocondrial ao redor de 150 mil anos atrás, na era do Homo sapiens idaltu.

O homem moderno, munido de um cérebro grande e de vasta capacidade intelectual, não tinha mais competidores e todos os obstáculos podiam ser vencidos. Ele foi então progressivamente colonizando outros continentes, além da África. Esse processo de expansão geográfica foi acompanhado de diversificação morfológica, fruto da adaptação aos diferentes ambientes. Surgiu assim um aparente paradoxo: somos todos muito parecidos e, ao mesmo tempo, muito diferen- 
tes. As grandes similaridades entre todos os humanos, e que nos distinguem com facilidade dos demais primatas, reportam, como visto acima, à nossa origem recente como espécie. Por outro lado, existem múltiplas variações morfológicas, tais como a cor da pele, a altura, a textura do cabelo e as características faciais, especialmente quando são comparados indivíduos pertencentes aos diferentes grupos nativos continentais (ninguém confundiria um africano de Botswana com um europeu da Noruega ou ainda com um índio Yanomami). Repetimos: tais diferenças refletem apenas a adaptação evolutiva das populações geograficamente diversificadas de Homo sapiens sapiens ao seu hábitat e não servem para atestar a existência de raças dentro de nossa espécie.

\section{Classificando pessoas}

O interesse em classificar as pessoas data da Antigüidade, e não é de se surpreender que as características morfológicas facilmente visíveis fossem utilizadas ao longo dos séculos para categorizar os indivíduos dentro de grupos discretos que, em algum momento, passaram a ser chamados de "raças". Foi o antropólogo alemão Johan Friedrich Blumenbach (1752-1841) quem primeiro nomeou as "variedades" dentro de nossa espécie. Ele reconheceu, com base na origem geográfica e em alguns parâmetros morfológicos, cinco raças principais: caucasóide, mongolóide, etiópica, americana e malaia. Por acreditar que a região do Cáucaso fosse o berço da humanidade, Blumenbach reconhecia na raça caucasóide (povos da Europa, do Oriente Médio, Norte da África e Índia) o “tipo” humano perfeito (Gould, 1994). Posteriormente, outras classificações foram propostas, sendo que as características morfológicas, especialmente a cor da pele, o tipo facial, o perfil do crânio, a textura e a cor dos cabelos, passaram a ter maior destaque. Tendo em vista a ênfase dada a estas características visíveis e facilmente identificáveis, não é surpreendente que logo as raças sugeridas por Blumenbach passassem a ser identificadas com base na quantidade de pigmentação da pele: caucasóide passou a ser sinônimo de branco e africano (etiópico) de negro. Além disso, foram feitas propostas mais complexas e que tinham a pretensão de explicar toda a diversidade morfológica humana. Nestes casos, o número de raças sugeridas aumentou consideravelmente, chegando a duzentas em algumas classificações (Armelagos, 1994)!

Richard Lewontin, utilizando polimorfismos genéticos clássicos (grupos sangüíneos, proteínas séricas e isozimas), publicou, há mais de três décadas, um estudo seminal que testou a validade do conceito de "raça" dentro da nossa espécie (Lewontin, 1972). Ele determinou que 85,4\% da variação era encontrada entre indivíduos de uma mesma população, 8,3\% entre populações dentro de uma mesma raça e apenas 6,3\% entre as chamadas raças, o que inviabilizaria a utilização do termo para a espécie humana em um contexto biológico. Inúmeras investigações posteriores corroboraram estes achados iniciais e esta idéia (por exemplo, Rosenberg e cols. 2002) e mostraram ainda que não há saltos quânticos nas distribuições alélicas entre as diferentes regiões da Terra, mas apenas gradientes. 
Uma exceção à regra de que a maior parte da variabilidade genética humana está concentrada dentro das populações é a cor da pele: $88 \%$ da variação pode ser encontrada entre regiões geográficas e apenas 12\% dentro das regiões (Relethford, 2002). A explicação para este fato é de que a cor da pele está sujeita à ação imperiosa da seleção natural e o resultado é uma adaptação notável das populações aos diferentes níveis de radiação ultravioleta vigentes nos diferentes continentes (Relethford, 1994). A cor da pele é determinada pela quantidade e tipo do pigmento melanina na derme e sua variação é controlada por apenas quatro a seis genes, dos quais o mais importante parece ser o gene do receptor do hormônio melanotrópico (Sturm e cols.; 1998; Rees, 2003). Ese número de genes é insignificantemente pequeno no universo dos cerca de 35 mil genes que existem no genoma humano. Da mesma maneira, acredita-se que outras características físicas externas (textura do cabelo, formato dos lábios e nariz etc.) devam estar sujeitas a fatores seletivos que ainda não foram claramente identificados. Sabemos que, assim como a cor da pele, estas características físicas das porções expostas do corpo dependem da expressão de um número pequeno de genes. Em resumo, as diferenças icônicas de "raças" correlacionam-se bem com o continente de origem (já que são selecionadas), mas não refletem variações genômicas generalizadas entre os grupos. Desta forma, deve ficar claro que se e quando a expressão "raça" for utilizada, ela irá representar uma construção social, política ou cultural, e não uma entidade biológica. Mesmo assim, as sociedades humanas construíram elaborados sistemas de privilégio e opressão baseados nessas insignificantes diferenças genéticas, que envolvem pouquíssimos genes.

\section{O encontro de ameríndios, europeus e africanos em terras brasileiras}

No final do século XV, os europeus, chegando às Américas, encontraram um continente habitado por milhões de pessoas, civilizações magníficas e cidades maiores que Madri ou Lisboa (Salzano e Bortolini, 2002). Isso não impediu, contudo, que o novo continente fosse conquistado a ferro e a fogo. E foram também os europeus que promoveram a vinda dos primeiros escravos africanos para as terras recém-descobertas. Nos quatro séculos que se seguiram ao desembarque de Colombo, cerca de doze milhões de africanos das regiões ao Sul do Saara foram transportados para as Américas. Destes, quatro milhões foram trazidos para o Brasil, sendo a grande maioria deles originários da costa Atlântica (África central e ocidental).

Devido a numerosas questões, incluindo as de natureza demográfica, uma intensa mistura gênica ocorreu entre colonizadores, colonizados e escravizados desde o início desse contato. Por séculos, a extensão dessa mescla foi mensurada por meio de critérios de aparência física. Inúmeros termos surgiram ao longo dos anos para definir e classificar pessoas que tinham como ancestrais africanos, europeus e ameríndios em várias combinações: mulato, cafuzo, caboclo, mame- 
luco, pardo e dezenas de outros, muitos dos quais impregnados de preconceitos. Entretanto, com a explosão da genética de populações propiciada pelos estudos em DNA (Cavalli-Sforza, 1998), foi possível observar que a extensão e a abrangência da mistura gênica eram muito maiores do que inicialmente se supunha com base apenas em critérios de natureza morfológica (Bortolini 1999; Pena e cols. 2000), e que havia uma correlação muito tênue entre cor da pele, textura dos cabelos, outros atributos físicos e ancestralidade (Parra e cols. 2003).

\section{Marcadores genéticos uniparentais}

Existem vários tipos de polimorfismos genéticos em nível do DNA, classificados de acordo com a sua natureza molecular e localização no genoma. Aqueles presentes em cromossomos autossômicos configuram-se como ótimos marcadores de individualidade. Podem também ser úteis como marcadores informativos de ancestralidade (MIAs), desde que a diferença nas freqüências alélicas entre duas populações supostamente parentais seja grande (Shriver e cols. 1997; Parra e cols. 1998). Já os polimorfismos uniparentais maternos (DNA mitocondrial) e paternos (determinadas regiões do cromossomo sexual Y) caracterizam-se por serem ótimos marcadores de linhagens, pois não há trocas de genes entre segmentos genômicos. Desta forma, os blocos de genes transmitidos às gerações seguintes permanecem inalterados nas matrilinhagens e patrilinhagens até que ocorra uma mutação, um evento raro. As mutações no DNA que ocorreram após a dispersão geográfica do homem moderno geraram variações que podem servir como marcadores geográficos por serem específicas de certas regiões do globo. Deve ser salientado, ainda, que o DNA mitocondrial (mtDNA) e o cromossomo $\mathrm{Y}$ fornecem informações complementares que podem alcançar dezenas de gerações no passado, o que permite resgatar a história de um povo por meio das migrações realizadas pelas mulheres e homens, respectivamente. Contudo, é importante lembrar que o mtDNA constitui uma parcela muito pequena da contribuição genética global dos antepassados de um indivíduo, o qual possui quatro avós, oito bisavós, dezesseis trisavós e assim por diante. Os estudos com o mtDNA revelam, dessa forma, informações sobre uma única antepassada e não sobre as demais. Analogamente, os polimorfismos do cromossomo Y fornecem informações sobre um único antepassado na linhagem masculina.

S. D. J. Pena e sua equipe de pesquisa na Universidade Federal de Minas Gerais realizaram um estudo que visava caracterizar, quanto aos marcadores do cromossomo Y e ao mtDNA, uma amostra de mais de duas centenas de pessoas autoclassificadas como brancas, oriundas de quatro das cinco regiões geográficas brasileiras: cinqüenta do Sudeste ( 99 pessoas no caso do mtDNA), 49 do Norte, 49 do Nordeste e 52 do Sul. Os resultados deste estudo filogeográfico, utilizando polimorfismos do cromossomo Y em brasileiros brancos (Carvalho-Silva e cols. 2001), estão arrolados na Tabela 1. A investigação também envolveu uma amostracontrole de 93 portugueses. Chama a atenção a contribuição mínima de cromos- 
somos Y típicos da África subsaariana (haplogrupo E3a*, com freqüência total de $2 \%$ ) ou de ameríndios (haplogrupo Q3*, não encontrado). Entre africanos e ameríndios as freqüências de E3a* e Q3* são da ordem de $53 \%$ e $78 \%$, respectivamente (Bortolini e cols. 2002). Por outro lado, a vasta maioria dos cromossomos $\mathrm{Y}$ observados em brasileiros brancos apresenta mutações típicas que os identificam como de origem européia.

Tabela 1 - Distribuição (em percentagem) dos haplogruposı do cromossomo Y em brasileiros brancos e numa amostra de Portugal

\begin{tabular}{c|c|c|c|c|c|c}
\hline Haplogrupo & \multicolumn{5}{|c|}{ Região do Brasil } & $\begin{array}{c}\text { Portugal } \\
(\%)\end{array}$ \\
\hline & $\begin{array}{c}\text { Norte } \\
(\%)\end{array}$ & $\begin{array}{c}\text { Nordeste } \\
(\%)\end{array}$ & $\begin{array}{c}\text { Sul } \\
(\%)\end{array}$ & $\begin{array}{c}\text { Sudeste } \\
(\%)\end{array}$ & $\begin{array}{c}\text { Total } \\
(\%)\end{array}$ & \\
\hline BCF & 12,2 & 18,4 & 28,8 & 12,0 & 18,0 & 12,9 \\
\hline $\mathbf{E}^{*}$ & 2,0 & 0 & 0 & 0 & 0,5 & 0 \\
\hline E3* $^{*}$ & 10,2 & 8,2 & 9,6 & 12,0 & 10,0 & 9,7 \\
\hline E3a $^{*}$ & 0 & 4,1 & 0 & 4,0 & 2,0 & 1,1 \\
\hline E3b3a $^{*}$ & 2,0 & 0 & 5,8 & 4,0 & 3,0 & 2,2 \\
\hline $\mathbf{J}^{*}$ & 16,3 & 2,0 & 3,8 & 10,0 & 8,0 & 6,5 \\
\hline O2b $^{*}$ & 2,0 & 0 & 0 & 0 & 0,5 & 0 \\
\hline $\mathbf{P}^{*}$ & 53,1 & 65,3 & 42,3 & 56,0 & 54,0 & 63,4 \\
\hline Q3 $^{*}$ & 0 & 0 & 0 & 0 & 0 & 0 \\
\hline R1a $^{*}$ & 2,0 & 2,0 & 9,6 & 0 & 3,5 & 2,2 \\
\hline R1b8 $^{*}$ & 0 & 0 & 0 & 2,0 & 0,5 & 2,2 \\
\hline № indivíduos & 49 & 49 & 52 & 50 & 200 & 93 \\
\hline
\end{tabular}

Nota: ${ }^{1}$ Haplogrupo representa um conjunto de haplótipos intimamente relacionados por apresentarem ancestral comum próximo.

Nesta Tabela foi utilizada a nomenclatura dos haplogrupos recomendada pelo Consórcio Internacional do Cromossomo Y (The International Y Chromosome Consortium, 2002).

Já a classificação da ancestralidade dos brancos brasileiros a partir das características moleculares do DNA mitocondrial (Tabela 2) mostrou-se bem diversa daquela encontrada com marcadores do Y: considerando o Brasil como um todo, 33\%, 28\% e 39\% das linhagens eram de origem ameríndia, africana e européia, respectivamente (Alves-Silva e cols. 2000). Como esperado, a freqüência ao longo das regiões variou significantemente: a maioria das linhagens mitocon- 
driais no Norte era de origem ameríndia (54\%), enquanto a ancestralidade africana era maior no Nordeste $(44 \%)$ e a européia no Sul $(66 \%)$.

Tabela 2 - Proporção de ancestralidade africana, ameríndia e européia em brasileiros brancos estimada através dos estudos com DNA mitocondrial.

\begin{tabular}{c|c|c|c|}
\hline Região & \multicolumn{3}{|c}{ DNA mitocondrial } \\
\hline Norte & $\begin{array}{c}\text { Ancestralidade } \\
\text { africana (\%) }\end{array}$ & $\begin{array}{c}\text { Ancestralidade } \\
\text { européia (\%) }\end{array}$ & $\begin{array}{c}\text { Ancestralidade } \\
\text { ameríndia (\%) }\end{array}$ \\
\hline Nordeste & 15 & 31 & 54 \\
\hline Sudeste & 44 & 34 & 22 \\
\hline Sul & 34 & 31 & 33 \\
\hline Total & 12 & 66 & 22 \\
\hline
\end{tabular}

Fonte: Alves-Silva e cols., 2000.

Em resumo, estes estudos filogeográficos com brasileiros brancos revelaram que a imensa maioria das patrilinhagens é européia, enquanto a maioria das matrilinhagens (mais de 60\%) é ameríndia ou africana. Evidencia-se, assim, um padrão de reprodução assimétrico (homem europeu com mulheres indígenas e africanas), o qual está de acordo com o que sabemos sobre o povoamento "pós-descobrimento" do Brasil. Em 1552, em carta ao rei D. João, padre Manuel da Nóbrega relata a falta de mulheres brancas no país e pede que elas sejam enviadas, para que os homens "casem e vivam [...] apartados dos pecados em que agora vivem". A coroa portuguesa tolerava relacionamentos entre portugueses e índias desde o início da colonização e até passou a estimular ativamente casamentos desse tipo por meio de um Alvará de Lei promulgado em 4 de abril de 1755 pelo Marquês do Pombal. Acredita-se que a idéia de Pombal era povoar o Brasil, garantindo sua ocupação territorial. Mas essa política, bastante liberal para a época, não foi estendida aos africanos. Contudo, sabe-se que, na prática, os relacionamentos entre portugueses e africanas persistiram em altos níveis.

\section{Proporção de pessoas com ancestralidade mitocondrial africana no Brasil}

Pelas freqüências regionais de haplogrupos mitocondriais africanos encontrados em brasileiros brancos e pelas proporções populacionais das várias regiões, pode-se (assumindo que a proporção de linhagens mitocondriais do CentroOeste seja a mesma do Sudeste) calcular uma proporção ponderada de $31 \%$ de linhagens mitocondriais africanas em indivíduos brancos no Brasil como um todo. Considerando este valor e as 90.647 .461 pessoas classificadas como brancas no 
censo de 2000, pode-se calcular que há aproximadamente 28 milhões de afrodescendentes entre os brasileiros autoclassificados como brancos. Para se ter uma contabilidade completa é preciso incluir neste cálculo a proporção de linhagens mitocondriais africanas presentes em brasileiros pretos e pardos. Bortolini et al. (1997) estudaram o mtDNA em 42 indivíduos negros (pretos + pardos). Entre os 34 indivíduos dos quais a origem da linhagem podia ser seguramente estabelecida, havia 27 matrilinhagens africanas $(80 \%)$ e apenas sete $(20 \%)$ que não eram de origem africana (cinco ameríndias e duas européias). Extrapolando essa porcentagem de $80 \%$ de linhagens africanas para a população negra (preta e parda) do censo de 2000 (76.419.233), pode-se, então, computar que aproximadamente 61 milhões de brasileiros negros têm matrilinhagens africanas. Somando-se esse número aos 28 milhões de brasileiros brancos que também apresentam linhagens africanas, conclui-se que 89 milhões de pessoas, ou seja, $52 \%$ dos brasileiros são comprovadamente afrodescendentes pelo lado materno. Obviamente, essas cifras têm limites de confiança muito amplos por serem baseadas em uma amostra pequena. Entretanto, elas permitem verificar que a proporção de afrodescendentes no Brasil é majoritária, sendo desta forma bastante superior aos $45 \%$ dos brasileiros que se declararam pretos ou pardos no censo de 2000.

\section{Marcadores genéticos biparentais, características morfológicas e ancestralidade}

Utilizando uma bateria de polimorfismos genéticos que apresentam grandes diferenças de freqüências alélicas (> 45\%) entre africanos e europeus, Parra e cols. (1998) mostraram que, em nível populacional era possível estimar, com grande precisão, o grau de mistura africana e européia de uma população norte-americana. S. D. J. Pena e seus colaboradores decidiram verificar então se este mesmo conjunto de locos seria capaz de, em nível individual, estimar um índice de ancestralidade africana (IAA) na população brasileira. Para isso foram selecionados dez dos marcadores informativos de ancestralidade (MIAs) utilizados no estudo americano (Parra e cols. 2003).

No intuito de verificar o poder de discriminação individual deste conjunto de dez polimorfismos, o estudo foi iniciado com a genotipagem de vinte amostras de DNA de portugueses da região do Porto e vinte amostras de africanos da ilha de São Tomé, localizada na costa ocidental do continente africano. Essas amostras foram escolhidas por pertencerem aos grupos dominantes de europeus e africanos que participaram na formação genética da população brasileira. Baseando-se nos resultados obtidos, foram determinados, para cada indivíduo, um "Índice de Ancestralidade Africana" (IAA), calculado pelo logaritmo da razão de verossimilhança do produto de determinado genótipo multilocal presente na população africana, sobre a verossimilhança deste genótipo na população européia (Shriver e cols. 1997). O conjunto de dez locos foi capaz de uma discriminação completa entre africanos e portugueses, não só ao nível populacional como individualmente, sem nenhuma sobreposição (Figura 1). 


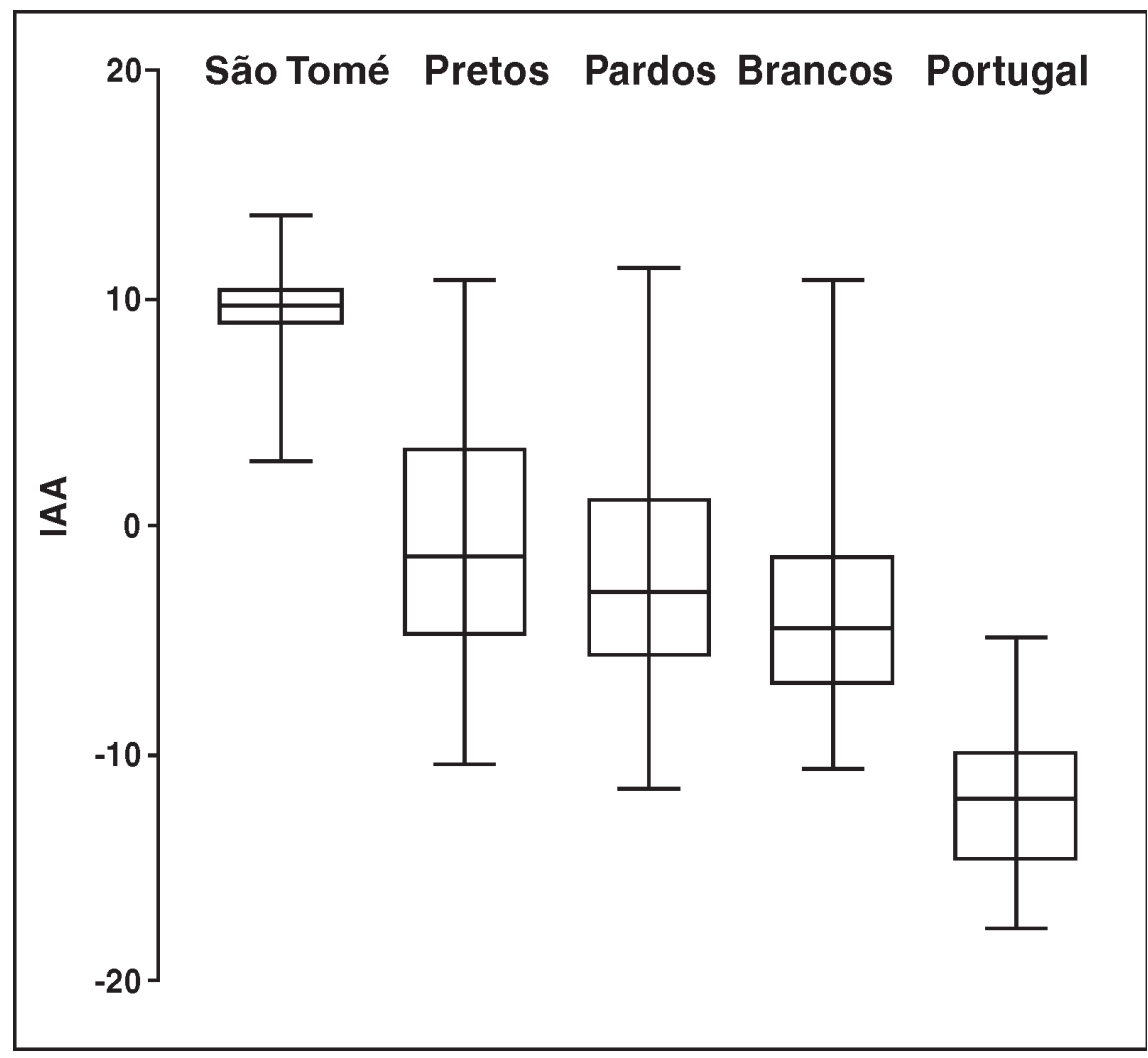

Figura 1

Índices de Ancestralidade Africana (IAA) em africanos de São Tomé, pretos, pardos e brancos de uma população rural do Vale do Jequitinhonha, em Minas Gerais (Queixadinha) e em portugueses. Cada grupo está representado por uma caixa cujos topo e assoalho marcam o quartil superior e inferior, com uma linha horizontal na mediana. As linhas verticais da caixa se estendem até a maior e menor obervação do grupo. (Modificado de Parra e cols., 2003)

Foram então estudados 173 indivíduos da população de Queixadinha, localizada no município de Caraí, no Vale do Jequitinhonha, região nordeste de Minas Gerais. Os indivíduos desse grupo haviam sido previamente analisados por dois observadores independentes para as seguintes características físicas icônicas, tradicionalmente usadas na classificação de brasileiros por cor: pigmentação da pele, cor e textura do cabelo, forma do nariz e lábios e cor dos olhos. De acordo com as suas características, cada um dos 173 indivíduos foi classificado como preto (trinta indivíduos), branco (29 indivíduos) ou pardo ( 114 indivíduos). No grupo pardo foram classificados aqueles que claramente apresentavam características intermediárias entre pretos e brancos, ou a respeito dos quais houve divergência entre os observadores. Interessantemente, os dados do IBGE para o município de Caraí mostram proporções, por autoclassificação, similares às do estudo feito. Após extração do DNA genômico a partir de alíquotas de sangue periférico, cada indivíduo foi tipado independentemente com os 10 MIAs e calculados os IAAs individuais (Figura 1). Os resultados mostraram uma alta variabilidade de valores 
de IAA nas três categorias morfológicas, mas agora com enorme superposição entre os mesmos. Por exemplo, um indivíduo de cor preta teve um valor de IAA de -10,5, o quarto menor em toda a amostra, enquanto o valor de IAA mais alto de toda a amostra $(11,3)$ foi de um indivíduo intermediário. Entretanto, a comparação de pretos e brancos com o teste $\mathrm{U}$ de Mann - Whitney ainda mostrou um valor modesto de significância $(\mathrm{z}=2,62 ; \mathrm{P}<0,01)$. Por outro lado, comparações dos brancos de Queixadinha com os portugueses e dos pretos com os africanos produziram resultados altamente significativos no teste $\mathrm{U}$ de Mann - Whitney (respectivamente, $\mathrm{z}=5.08, \mathrm{P}<0.0001 \mathrm{e} \mathrm{z}=-5.24, \mathrm{P}<0.0001$ ). Assim, as diferenças dos valores de IAA entre os brancos e pretos de Queixadinha são pequenas e várias ordens de magnitude menores que as diferenças entre europeus e africanos.

Esses resultados em uma população rural de Minas Gerais não podiam ser ingenuamente extrapolados para todo o Brasil. Assim, o estudo foi estendido a uma amostra cosmopolita de duzentos indivíduos autoclassificados como brancos, com origens nas principais regiões geográficas do país, ou seja, Sudeste, Nordeste, Norte e Sul. Esta amostra é basicamente a mesma que havia sido usada para os estudos anteriores em brasileiros com marcadores do cromossomo Y (CarvalhoSilva e cols. 2001) ou seqüenciamento de DNA mitocondrial (Alves-Silva e cols. 2000). A distribuição dos valores de IAA novamente mostrou superposição e grande similaridade. A região Sul do Brasil, caracterizada pelos altos índices de imigração européia nos séculos XIX e XX, apresentou o IAA mediano mais baixo de todas as regiões $(-9.11)$, que ainda é significantemente maior que os valores dos portugueses $(\mathrm{z}=3.04, \mathrm{P}=0.002)$.

Esses estudos demonstram que esses marcadores genéticos autossômicos permitiram, com precisão, uma classificação ao nível individual do grau de ancestralidade genômica africana. Mostra ainda que, na população brasileira analisada, o alto índice de mescla gênica faz com que características físicas icônicas, como cor da pele, olhos, cabelos, lábios e narizes, sejam marcadores significativamente pobres na determinação da origem geográfica dos ancestrais de um indivíduo, quando comparados com estudos em populações africanas e européias, consideravelmente menos mescladas.

\section{Proporção de pessoas com ancestralidade genômica africana no Brasil}

Partindo dos dados gerados pelo estudo acima (Parra e cols. 2003) estimamos o grau de mistura gênica através do método de máxima verossimilhança de Wang (2003) para as populações brancas das várias regiões brasileiras, bem como para brancos, pardos e pretos da comunidade rural de Queixadinha. Os resultados são mostrados na Tabela 3. Como esperado, os maiores valores de ancestralidade africana foram encontrados nas regiões Nordeste e Sudeste, da mesma forma que já havia ocorrido com os dados do mtDNA (ver Tabela 2). As regiões Sul e Norte, por sua vez, mostram valores menores de ancestralidade africana e 
diferem significativamente nas proporções de origem ameríndia e européia (Tabela 2). Para Queixadinha, o conjunto de indivíduos classificados como pretos apresentou uma proporção de ancestralidade africana de $51 \%$, enquanto para os pardos este valor foi de $44 \%$. Essas cifras revelam que os pardos apresentam maior semelhança nos níveis de ancestralidade africana, com os pretos, o que dá suporte científico à estratégia de mobilização política empregada pelo movimento negro do Brasil, que consiste em agrupar indivíduos pretos e pardos na categoria negros (Telles, 2003).

Tabela 3 - Níveis de ancestralidade africanaı (em percentagem) estimados para a população brasileira branca de várias regiões, e para brancos, pardos e pretos da comunidade rural de Queixadinha.

\begin{tabular}{l|l|l|c|c}
\cline { 4 - 4 } \multicolumn{2}{c}{} & \multicolumn{2}{c}{ MIAs } \\
\cline { 4 - 5 } & & Brancos & 32 & LC $^{2}$ \\
\hline Queixadinha & & Pardos & 44 & $15-52$ \\
\hline & & Pretos & 51 & $30-61$ \\
\hline & Norte & Brancos & 22 & $36-66$ \\
\hline Brasil & Nordeste & Brancos & 29 & $12-35$ \\
\hline & Sudeste & Brancos & 32 & $15-48$ \\
\hline & Sul & Brancos & 12 & $16-53$ \\
\hline
\end{tabular}

Notas: ${ }^{1}$ Estimativa gerada a partir dos dados de dez marcadores informativos de ancestralidade (MIAs), utilizando-se o método da máxima verossimilhança de Wang, 2003.

${ }^{2}$ Limites de confiança de $95 \%$.

Da mesma forma como estimamos o número de pessoas no Brasil que apresentam ancestralidade mitocondrial africana, fizemos a estimativa do número de brasileiros com ancestralidade africana utilizando os dados de MIAs e o programa Structure (Pritchard e cols. 2000). Dadas as duas populações parentais com freqüências alélicas conhecidas, este programa calcula a contribuição relativa das mesmas para o genótipo de cada indivíduo. Nesse caso específico, Structure estimou a proporção de ancestralidade africana em cada indivíduo das amostras de brasileiros brancos das quatro regiões do país. Os resultados podem ser vistos na Tabela 4. Os valores encontrados são instigantes. Mais de $75 \%$ dos brancos do Norte, Nordeste ou Sudeste apresentam ancestralidade africana superior a 10\%. Mesmo no Sul, com seu marcante histórico de imigração européia, este valor é na ordem de $49 \%$. Para comparação calculamos, a partir dos dados fornecidos por Shriver e cols. (2003), os valores para brancos norte-americanos: apenas 11\% deles apresentam ancestralidade africana acima de $10 \%$. 
Tabela 4 - Proporção de ancestralidade africana estimada pelo programa Structure em brasileiros autoclassificados como brancos

\begin{tabular}{|c|c|c|c|c|c|c|}
\hline \multirow{2}{*}{$\begin{array}{c}\text { Ancestralidade } \\
\text { africana }\end{array}$} & \multicolumn{4}{|c|}{ Brancos } & \multirow[t]{2}{*}{ Pretos $_{1}$} & \multirow{2}{*}{$\begin{array}{c}\text { Brancos } \\
\text { EUA2 }^{2}\end{array}$} \\
\hline & Sul & Norte & Nordeste & Sudeste & & \\
\hline$>10 \%$ & 49,1 & 75,5 & 80,0 & 89,0 & 96,7 & 10,7 \\
\hline$>20 \%$ & 29,4 & 57,1 & 64,0 & 78,7 & 93,3 & 2,1 \\
\hline$>30 \%$ & 15,9 & 46,9 & 54,0 & 63,8 & 86,7 & 0 \\
\hline$>40 \%$ & 9,8 & 26,5 & 36,0 & 46,8 & 80,0 & 0 \\
\hline$>50 \%$ & 3,9 & 18,4 & 26,0 & 25,5 & 73,3 & 0 \\
\hline$>60 \%$ & 0 & 8,2 & 18,0 & 19,1 & 63,3 & 0 \\
\hline$>70 \%$ & 0 & 2,0 & 6,0 & 10,6 & 40,0 & 0 \\
\hline$>80 \%$ & 0 & 2,0 & 2,9 & 4,2 & 20,3 & 0 \\
\hline$>90 \%$ & 0 & 0 & 0 & 2,0 & 13,3 & 0 \\
\hline
\end{tabular}

Notas: ${ }^{1}$ Para efeitos de comparação foram incluídos na análise os indivíduos pretos da amostra de Queixadinha, Estado de Minas Gerais (ver texto).

${ }^{2}$ Estados Unidos da América. Estimativas obtidas a partir dos dados compilados de Shriver e cols., 2003.

Por outro lado, apenas 73\% dos pretos de Queixadinha apresentam um proporção superior a $50 \%$ de ancestralidade africana. Este dado mostra, mais uma vez, a intensidade da mistura gênica que ocorreu na formação do povo brasileiro, pois, neste caso, para 27\% dos classificados como pretos em Queixadinha, a ancestralidade majoritária não é a africana.

Se definirmos como afrodescendentes toda pessoa com mais de $10 \%$ de ancestralidade africana e usarmos os valores apresentados na Tabela 4, podemos estimar a proporção de afrodescendentes na população brasileira como um todo (Tabela 5). Os resultados são impressionantes: $87 \%$ dos brasileiros, ou seja, cerca de 146 milhões de pessoas pelo censo de 2000, apresentam mais de $10 \%$ de ancestralidade africana. Os dados mostram também que $48 \%$ dos afrodescendentes brasileiros se autoclassificam como brancos. Na região Sul, mais de dois terços $(72 \%)$ dos afrodescendentes consideram-se brancos. A definição quantitativa de afrodescendente como qualquer pessoa com mais de $10 \%$ de ancestralidade africana é claramente arbitrária. A Tabela 6 mostra os valores absolutos, considerando o número de brasileiros com diferentes proporções de ancestralidade africana. A conclusão impressionante é que pelo menos 77 milhões de pessoas em nosso país apresentam mais de $90 \%$ de ancestralidade africana! Obviamente estas estimativas foram feitas por extrapolação de resultados experimentais com amostras relativa- 
mente pequenas e, conseqüentemente, têm limites de confiança bastante amplos. Entretanto, elas demonstram veementemente a enorme contribuição africana para a formação da população brasileira.

Tabela 5 - Estimativa do número total de afrodescendentes no Brasil com base no censo de 2000 do IBGE.

\begin{tabular}{|c|c|c|c|c|c|}
\hline & Sul & Norte & Nordeste & $\begin{array}{c}\text { Sudeste }+ \\
\text { Centro-Oeste }\end{array}$ & Total \\
\hline $\begin{array}{l}\text { População } \\
\text { no Censo } \\
\text { de } 2000\end{array}$ & 25.013.161 & 12.879 .100 & |47.692.349 & 83.697 .951 & 169.282 .561 \\
\hline $\begin{array}{c}\text { Número de } \\
\text { indivíduos } \\
\text { autodeclara- } \\
\text { dos brancos } \\
\text { no censo } \\
\text { de } 2000\end{array}$ & 20.914.143 & 3.608 .833 & $\mid 15.704 .580$ & 50.748 .919 & 90.976 .475 \\
\hline $\begin{array}{c}\text { Proporção } \\
\text { dos brancos } \\
\text { com mais de } \\
10 \% \text { de } \\
\text { ancestralida- } \\
\text { de africana }\end{array}$ & $49,0 \%$ & $75,5 \%$ & $80,0 \%$ & $89,0 \%$ & \\
\hline $\begin{array}{c}\text { Número de } \\
\text { indivíduos } \\
\text { brancos com } \\
>10 \% \\
\text { ancestralida- } \\
\text { de africana }\end{array}$ & 10.247.930 & 2.724 .669 & 12.563 .664 & 45.166 .538 & 70.702 .801 \\
\hline $\begin{array}{c}\text { Número de } \\
\text { indivíduos } \\
\text { autodeclara- } \\
\text { dos pardos + } \\
\text { pretos no } \\
\text { censo de } \\
2000\end{array}$ & 3.808.419 & 8.881 .771 & 31.349 .893 & 31.599 .680 & 75.639 .763 \\
\hline $\begin{array}{c}\text { Total de } \\
\text { afrodescen- } \\
\text { dentes }\end{array}$ & 14.056.349 & 11.606 .440 & |43.913.557| & 76.766 .218 & 146.342 .564 \\
\hline $\begin{array}{c}\% \\
\text { Afrodescen- } \\
\text { dentes }\end{array}$ & $56 \%$ & $90 \%$ & $92 \%$ & $92 \%$ & $86 \%$ \\
\hline
\end{tabular}


Tabela 6 - Número absoluto de brasileiros com diferentes proporções de ancestralidade africana.

\begin{tabular}{c|c|c}
\hline Ancestralidade africana & $\begin{array}{c}\text { Número de } \\
\text { afrodescendentes } \\
\text { (em milhões) }\end{array}$ & $\begin{array}{c}\text { Proporção de } \\
\text { afrodescendentes } \\
\text { no Brasil }\end{array}$ \\
\hline$>10 \%$ & 146 & $86 \%$ \\
\hline$>20 \%$ & 134 & $79 \%$ \\
\hline$>30 \%$ & 121 & $71 \%$ \\
\hline$>40 \%$ & 108 & $54 \%$ \\
\hline$>50 \%$ & 94 & $56 \%$ \\
\hline$>60 \%$ & 88 & $48 \%$ \\
\hline$>70 \%$ & 82 & $46 \%$ \\
\hline$>80 \%$ & 78 & $45 \%$ \\
\hline
\end{tabular}

\section{Pode a genética definir quem deve se beneficiar} das cotas universitárias e das ações afirmativas?

Grande parte da discussão da classificação racial humana e sua importância social gravita em torno do binômio aparência física/origem geográfica, ou, resumidamente, cor/ancestralidade. A própria expressão "raça” é usada ora em um sentido, ora em outro. No contexto morfológico, fenotípico, classificam-se as pessoas como pertencentes a um certo grupo por meio de um conjunto de caracteres físicos (por exemplo, cor da pele ou textura do cabelo). Assim, fala-se da raça negra, da raça branca etc. No Brasil, a palavra "cor" é usada como um sinônimo nesse sentido. "Raça” pode também denotar origem em uma região do globo, assumindo o significado de “ancestralidade geográfica” - fala-se então de uma raça africana, raça oriental etc. (Pena, 2002). Essa dicotomia fica bem evidente, por exemplo, quando se lê o trabalho de Oracy Nogueira (1955) que distinguiu o preconceito "de marca" do preconceito "de origem". O primeiro vimitiza a aparência e se baseia nos traços físicos do indivíduo, enquanto o segundo depende da percepção de que o indivíduo descende de certo grupo étnico. Nogueira associou o preconceito “de marca” com o Brasil e o preconceito “de origem" com os Estados Unidos.

Estamos vivendo um momento importante de reavaliação das relações entre os grupos de identidade em nosso país. O crescimento da consciência negra e a discussão em torno dos temas relacionados a políticas de cotas no Brasil têm causado mudanças, inclusive na nossa própria etnosemântica, com uma crescente 
popularização da expressão afrodescendente, a qual desloca o eixo de discussão da aparência física para a ancestralidade (Kabengelê Munanga, comunicação pessoal). É neste contexto que se insere este trabalho, pois procura mostrar que os afrodescendente são em número bem maior do que aqueles que aparentam ser por suas características físicas, chegando ao número impressionante de 146 milhões de pessoas. Procurou-se também demonstrar que muitos dos que se identificam como negros apresentam uma proporção significativa de ancestralidade européia. Dessa maneira, não é nada surpreendente que existam confusões e problemas relacionados aos critérios adotados para definir quem deve ser beneficiado pelas políticas de ação afirmativa no Brasil.

Lembramos aqui, mais uma vez, que raças humanas não existem do ponto de vista genético ou biológico (Templeton, 1999). Apenas $5 \%$ da variação genômica humana ocorre entre as chamadas "raças". Ademais, somente $0,01 \%$ do genoma humano varia entre dois indivíduos. Em outras palavras, toda a discussão racial gravita em torno de $0,0005 \%$ do genoma humano! Por outro lado, mesmo não tendo o conceito de raças pertinência biológica alguma, ele continua a ser utilizado, qua construção social e cultural, como um instrumento de exclusão e opressão. Independente dos clamores da genética moderna de que a cor do indivíduo é estabelecida por apenas um punhado de genes totalmente desprovidos de influência sobre a inteligência, talento artístico ou habilidades sociais, a pigmentação da pele ainda parece ser um elemento predominante da avaliação social de um indivíduo e talvez a principal fonte de preconceito.

Tendo em vista a nova capacidade de se quantificar objetivamente, por meio de estudos genômicos, o grau de ancestralidade africana de cada indivíduo, pode a genética definir quem deve se beneficiar das cotas universitárias e demais ações afirmativas? Prima facie poderia parecer que sim, mas a nossa resposta é um enfático NÃO. Vejamos o porquê. Acreditamos que a genética moderna pode oferecer subsídios para as decisões políticas e que o perfil genético da população brasileira certamente deve ser levado em conta em decisões políticas. Por outro lado, a genética não pode arrogar-se um papel prescritivo explícito. Para tornar este ponto mais claro, vamos fazer uma analogia com o aconselhamento genético, que constitui a dimensão clínica da genética humana.

O aconselhamento genético é o processo por meio do qual o geneticista clínico fornece a seus pacientes e suas famílias informações a respeito de uma dúvida genética que os aflija. O objetivo do aconselhamento genético é ajudar as próprias pessoas a tomarem decisões informadas sobre casamento, reprodução ou condutas médicas com base em conhecimento genético sólido. O processo de aconselhamento genético é fundamentalmente não-diretivo: o geneticista fornece a informação genética, mas cabe ao paciente ou à família a decisão de conduta com base na interpretação dos informes recebidos de acordo com a sua história de vida, seus sofrimentos e sua percepção dos riscos e dos benefícios das várias alternativas. 
Analogamente, a informação genética sobre a estrutura da população brasileira deve ser considerada apenas como um subsídio para o processo de tomada de decisões. Não compete à genética fazer prescrições sociais. A definição sobre quem deve se beneficiar das cotas universitárias e das ações afirmativas no Brasil deverá ser resolvida na esfera política, levando em conta a história do país, o sofrimento de seus vários segmentos e análises de custo e benefício.

No início do século XX, o embriologista Ernst Häckel (1834-1919), cunhou o desditoso aforismo a política é biologia aplicada. Um político na Alemanha se encantou tanto com esta frase que ele a adotou como um de seus slogans - seu nome era Adolf Hitler. A moral dessa estória é que a genética deve contentar-se em fornecer dados científicos sólidos que ajudem a sociedade como um todo a tomar decisões políticas informadas.

\section{Nota}

I No Brasil, de acordo com Telles (2003), existem três grandes sistemas associados à chamada "classificação racial": (1) os censos do IBGE que distinguem três categorias, brancos, pardos e pretos, além de amarelos e indígenas); (2) o discurso popular que utiliza uma nomenclatura ampla, inclusive o termo bastante ambíguo“"moreno" e (3) o sistema do movimento negro que distingue apenas duas categorias, reunindo pardos e pretos como "negros". O governo brasileiro parece ter optado por esta última (Telles, 2003). Mais recentemente, a expressão afrodescendente está sendo incorporada a esta etnosemântica (Kabengelê Munanga, comunicação pessoal). Neste trabalho, usamos as expressões "branco, pardo e preto", especialmente quando utilizamos dados dos censos, e a palavra "negro" para o conjunto mais amplo, envolvendo pretos e pardos. Também utilizamos o vocábulo "afrodescendente" para se referir a todas as pessoas com ancestrais africanos, independente da cor da pele.

\section{Bibliografia}

ALVES-SILVA, J.; SILVA SANTOS, M. Da; GUIMARAES, P. E.; FERREIRA, A. C.; BANDELT, H. J.; PENA, S. D. e PRADO, V. F. "The Ancestry of Brazilian mtDNA Lineages". Am J Hum Genet., n. 67, 2000, pp. 444-461.

AMERICAN ANTHROPOLOGICAL ASSOCIATION. Statement on "Race". 1988. http://www.aaanet.org/stmts/racepp.htm.

ARMELAGOS, G. J. “Racism and Physical Anthropology: Brues's Review of Barkan's The Retreat of Scientific Racism". Am. J. Phys. Anthropol., n. 93, 1994, pp. 381-383.

BORTOLINI, M. C.; ZAGO, M. A.; SALZANO, F. M.; SILVA-JUNIOR, W. A.; BONATTO, S. L.; SILVA, M. C. da e WEIMER, T. A. "Evolutionary and Anthropological Implications of Mitochondrial DNA Variation in African Brazilian Populations". Hum. Biol., n. 69, 1997, pp. 141-159. 
BORTOLINI, M. C.; SALZANO, F. M.; BAU, C.; LAYRISSE, Z.; PETZL-ERLER, M. L.; TSUNETO, L. T.; HILL, K.; HURTADO, A. M.; CASTRO-DE-GUERRA, D.; BEDOYA, G. e RUIZ-LINARES, A. "Y-chromosome Biallelic Polymorphisms and Native American Population Structure". Ann.Hum. Genet., n. 66, 2002, pp. 255-259.

BORTOLINI, M. C. "Breve visão sobre a gênese e a evolução das populações latinoamericanas". Genética para que te quero? Porto Alegre, Editora da Universidade Federal do Rio Grande do Sul, 1999, pp. 57-61.

CANN, R. L.; STONEKING, M. e WILSON, A. C. "Mitochondrial DNA and Human Evolution". Nature, n. 325. 1987, pp. 31-36.

CARVALHO-SILVA, D. R.; SANTOS, F. R.; ROCHA, J. e PENA, S. D. "The Phylogeography of Brazilian Y-chromosome Lineages”. Am. J. Hum. Genet., n. 68, 2001, pp. 281-286.

CAVALLI-SFORZA, L. L. “The DNA Revolution in Population Genetics". Trends Genet., n. 14, 1998, pp. 60-65.

CORREAA, H. "Em MS, foto diz quem entra por cotas para negros". Folha de S. Paulo, 15/12/2003. http://wwwl.folha.uol.com.br/folha/educacao/ult305ul4591.shtml

GOULD, S. J. “The Geometer of Race”. Discover, n. 15, 1994, pp. 65-69.

HAILE-SALASSIE, Y.; ASFAW, B. e WHITE, T. D. “Hominid Cranial Remains from upper Pleistocene Deposits at Aduma, Middle Awash, Ethiopia”. Am. J. Physical. Anthropol., n. 123, 2004, pp. 1-10.

LEWONTIN, R. C. “The Apportionment of Human Diversity”. Evol. Biol., n. 6, 1972, pp. 381-398.

MUNANGA, K. "Políticas de ação afirmativa em benefício da população negra no Brasil - um ponto de vista em defesa de cotas”. Revista Espaço Acadêmico, mar. 2003. http://www.espacoacademico.com.br/022/22 cmunanga.htm

NOGUEIRA, O. "Preconceito racial de marca e preconceito racial de origem". Anais do XXXI Congresso Internacional dos Americanistas. São Paulo, Anhembi, vol. 1, 1955.

PARRA, E. J.; MARCINI, A.; AKEY, J.; MARTINSON, J.; BATZER, M. A.; COOPER, R.; FORRESTER, T.; ALLISON, D. B.; DEKA, R.; FERRELL, R. E. e SHRIVER, M. D. "Estimating African American Admixture Proportions by Use of Populationspecific Alleles". Am.J. Hum. Genet., n. 63, 1998, pp. 1839-1851.

PARRA, F. C.; AMADO, R. C.; LAMBERTUCCI, J. R.; ROCHA, J.; ANTUNES, C. M.; PENA, S. D. "Color and Genomic Ancestry in Brazilians”. Proc. Natl. Acad. Sci. USA, n. 100, 2003, pp. 177-182.

PENA, S. D. J.; CARVALHO-SILVA, D. R.; ALVES-SILVA, J.; PRADO, V. F. e SANTOS, F. R. "Retrato molecular do Brasil”. Ciência Hoje, 27(159), 2000, pp. 16-25.

PENA, S. D. J. “Os múltiplos significados da palavra raça”. Folha de S. Paulo, 21/12/ 2002.

PRITCHARD, J. K.; STEPHENS, M. e DONNELLY, P. Inference of Population Structure Using Multilocus Genotype Data”. Genetics, n. 155, 2000, pp. 945-959. 
REES, J. L. "Genetics of Hair and Skin Color". Annu. Rev. Genet., n. 37, 2003, pp. 67-90.

RELETHFORD, J. H. “Craniometric Variation among Modern Human Populations”. Am. J. Phys. Anthropol., n. 95, 1994, pp. 53-62.

RELETHFORD, J. H. “Apportionment of Global Human Genetic Diversity Based on Craniometrics and Skin Color". Am. J. Phys. Anthropol., n. 118, 2002, pp. 393-398.

ROSENBERG, N. A.; PRITCHARD, J. K.; WEBER, J. L.; CANN, H. M.; KIDD, K. K.; ZHIVOTOVSKY, L. A. e FELDMAN, M. W. “Genetic Structure of Human Populations”. Science, n. 298, 2002, pp. 2381-2385.

SALZANO, F. M. e BORTOLINI, M. C. Evolution and Genetics of Latin American Populations. Cambridge, Cambridge University Press, 2002.

SHRIVER, M. D.; PARRA, E. J.; DIOS, S.; BONILLA, C.; NORTON, H.; JOVEL, C.; PFAFF, C.; JONES, C.; MASSAC, A.; CAMERON, N.; BARON, A.; JACKSON, T.; ARGYROPOUlOS, G.; JIN, L.; HOGGART, C. J.; MCKEIGUE, P. M. e KITTLES, R. A. "Skin Pigmentation, Biogeographical Ancestry and Admixture Mapping”. Hum Genet., n. 112, 2003, pp. 387-399.

SHRIVER, M. D.; SMITH, M. W.; JIN, L.; MARCINI, A.; AKEY, J. M.; DEKA, R. e FERRELL, R. E. "Ethnic-affiliation Estimation by Use of Population-specific DNA Markers". Am.J. Hum. Genet., n. 60, 1997, pp. 957-964.

STURM, R. A.; BOX, N. F. e RAMSAY, M. "Human Pigmentation Genetics: The Difference is Only Skin Deep”. Bioessays, n. 20, 1998, pp. 712-721.

TELLES, E. Racismo à brasileira: uma nova perspectiva sociológica. Rio de Janeiro, Relume Dumará, 2003. 347 pp.

TEMPLETON, A. R. "Human Races: A Genetic and Evolutionary Perspective”. Am. Anthropol., n. 100, 1999, pp. 632-650.

WANG, J. "Maximum-likelihood Estimation of Admixture Proportions from Genetic Data”. Genetics, n. 164, 2003, pp. 747-765.

WHITE, T. D.; ASFAW, B.; DEGUSTA, D.; GILBERT, H.; RICHARDS, G. D.; SUWA, G. e HOWELL, F. C. "Pleistocene Homo sapiens from Middle Awash, Ethiopia". Nature, n. 423, 2003, pp. 742-747.

Y CHROMOSOME CONSORTIUM. "A Nomenclature System for the Tree of Human Y-chromosomal Binary Haplogroups”. Genome Res., n. 12, 2002, pp. 339-348.

RESUMO - NESTE TRABALHO nós usamos o instrumental da genética molecular e da genética de populações para estimar quantitativamente a contribuição africana para a formação do povo brasileiro. Examinamos dois compartimentos genômicos: o DNA mitocondrial, de herança matrilínea, e o DNA nuclear, de herança bi-parental. Os estudos mitocondriais revelaram que aproximadamente $30 \%$ dos brasileiros autoclassificados como brancos e $80 \%$ dos negros apresentam linhagens maternas características da áfrica subsaariana. A partir destes dados, estimamos que pelo menos 89 milhões de brasileiros são afrodescendentes, um número bem superior aos 76 milhões de pessoas que se declararam 
negros (pretos e pardos) no censo de 2000 do IBGE. As análises de polimorfismos nucleares com marcadores "informativos de ancestralidade" mostraram resultados mais expressivos ainda. Usando estudos de brasileiros autoclassificados como brancos de várias regiões do Brasil, estimamos que aproximadamente 146 milhões de brasileiros (86\% da população) apresentam mais de $10 \%$ de contribuição africana em seu genoma. Estes números devem ser levados em conta nas discussões sobre ações afirmativas no Brasil, mas em um sentido descritivo e não prescritivo.

ABSTRACT - IN THIS ARTICLE we used tools of molecular and population genetics to estimate quantitatively the African contribution for the formation of the Brazilian population. We examined two genomic compartments: mitochondrial DNA (mtDNA), maternally inherited, and nuclear DNA, inherited from both parents. The studies using mtDNA showed that about $30 \%$ of Brazilians self-classified as White and $80 \%$ of Brazilian Negroes carry maternal lineages typical of Sub-Saharan Africa. Using these data we could estimate that at least 89 million Brazilians are afrodescendants, a number considerably larger than the 76 million individuals self-classified as Negro in the 2000 census. The analyses on nuclear polymorphisms employed "ancestry informative" markers and showed even more striking results. On the basis of studies in individuals self-classified as White from several Brazilian regions, we estimated that approximately 146 million Brazilians (86\% of the population) had more than $10 \%$ African contribution to their genome. These numbers should be taken into account in discussing affirmative action programs in Brazil, but in a descriptive rather than a prescriptive sense.

Sérgio Danilo Junho Pena é médico-geneticista e professor-titular do Departamento de Bioquímica e Imunologia da Universidade Federal de Minas Gerais. É autor de mais de duzentos trabalhos científicos e coordenador do livro Homo brasilis: aspectos genéticos, linguisticos, históricos e socioantropológicos da formação do povo brasileiro (Ribeirão Preto, Funpec, 2002).

Maria Cátira Bortolini é bióloga e professora-adjunta do Departamento de Genética da Universidade Federal do Rio Grande do Sul. É autora de inúmeros trabalhos científicos e co-autora do livro The Evolution and Genetics of Latin American Populations (Cambridge, Cambridge University Press, 2002).

Texto recebido e aceito para publicação em 17 de fevereiro de 2003. 